\title{
Our experiences with a single injection axillary block technique
}

\author{
Yonca Yanli, Mehtap Ozdemir, Nurten Bakan \\ Department of Anesthesiology and Reanimation, Umraniye Training and Research Hospital, Istanbul, Turkey
}

\begin{abstract}
OBJECTIVE: Axillary plexus block is one of the widely used technique for upper extremity surgery. In this study, we retrospectively evaluated the single injection axillary plexus block technique we used in our rutine anesthesia practice, between August 2010-March 2011.
\end{abstract}

METHODS: Medical records of ASA I-III, 4017 female and 23 male patients who underwent elective single injection axillary block performed by neurostimulation technique in elective distal part of the arm, forearm and hand surgeries were evaluated, retrospectively. Axillary block was performed with a nerve stimulator, and a 22 G, $50 \mathrm{~mm}$ insolated needle. The needle was inserted immediately superior to axillary artery, advanced through the lateral border of the pectoralis major muscle and to the most proximal part of the axilla. The local anesthetic mixture ( $1 \%$ lidocaine $20 \mathrm{ml}+0.25 \%$ bupivacaine $15 \mathrm{ml}$ ) was injected to the place (point) where the distal motor responses of the median and ulnar nerves were elicited at the same time, before dropping the stimulation current down to $0.5 \mathrm{~mA}$. In our study, demographic data, motor and sensory block times, the success rate and the complications of the block were evaluated.

RESULTS: The mean block performance time was $1.21 \pm 0.39$ min in our 40 patients. The onset time of the motor block was $14.20 \pm 4.96 \mathrm{~min}$ and the sensory block was $17.19 \pm 2.71 \mathrm{~min}$, respectively. The success rate of the block was 97.5 percent. No complication was found during 24 hours postoperatively. The sensory and motor functions returned properly in all patients.

CONCLUSION: In our study we found that the single injection axillary block tecnique was easy to perform with its higher success, and lower complication rates. Therefore we concluded that axillary block should be supported in appropriate cases.

Key words: Anesthetics, axillary nerve block, brachial plexus, local

$\mathrm{P}$ eripheral nerve blocks are frequently used techniques in upper, and lower ekstremite surgery. For upper extremity surgery, brachial plexus block is preferred due to its advantages as application with ease with lower complication rates, and shorter hospital stay $[1,2,3]$. Various approaches can be used for brachial plexus block. Dependent on the surgical field, and individual experiences, choice of type of

Received: June 06, 2014 Accepted: July 08, 2014 Online: August 03, 2014

Correspondence: Yonca YANLI. Umraniye Egitim ve Arastirma Hastanesi, Anesteziyoloji ve Reanimasyon Klinigi, Istanbul, Turkey.

Tel: +90 216 - 6321818 e-mail: yoncayanli@yahoo.com

(c) Copyright 2014 by Istanbul Northern Anatolian Association of Public Hospitals - Available online at www.kuzeyklinikleri.com 
the block varies $[3,4]$. Axillary approach to brachial plexus provides adequate anesthesia in the surgeries performed on the distal arm, and hand. Besides, thanks to its ease of application, and reliability, its use is becoming more prevalent $[2,5,6,7]$.

For the determination of the location of brachial plexus, loss of resistance, transarterial injection, paresthesia, neurostimulation, and ultrasonographic techniques can be used $[2,4]$. Thus brachial plexus can be blocked using single, double or multiple injections $[2,4,5]$. For a successful block local anesthetic solution should be injected into the nerve sheath, rather than directly into the nerve. In the axillary region, brachial plexus divides into median, radial, and ulnar nerves, However all of these nerves are contained in the same neurovascular sheath $[2,8]$.

In our study, we aimed to evaluate retrospectively axillary block method using neurostimulation method applied with a single dose of the anesthetic agent injected into the region where a combined distal motor response of median, and ulnar nerves is elicited.

\section{MATERIALS AND METHODS}

After the informed consent of the patient was obtained, axillary block evaluations of 40 ASA I-III patients aged $>17$ years who had undergone surgi- cal interventions on the distal $1 / 3$ of the arm, forearm, and hand in the operative room of the clinic of orthopedics, between August 2010, and March 2011 were analyzed retrospectively. We have detected that the patients with a body mass index of $<$ $40 \mathrm{~kg} / \mathrm{m}^{2}$ without any contraindication for regional anesthesia, neurological, and psychiatric disorder, bleeding diasthesis, and allergy to local anesthetics had received axillary block.

In the preoperative preparation room, in patients who will receive peripheral block, peripheral vascular access is opened using an 18-20 G catheter, and for premedication IV midazolam is administered at a dose of $0.03 \mathrm{mg} / \mathrm{kg}$. In our axillary block applications, the arm to be intervened is brought into $90^{\circ}$ abduction with the body, and elbow into $90^{\circ}$ flexion. Following sterilization, and local anesthesia, axillary artery is palpated in the axillary fossa to the most proximal to the junction of pectoralis major, and coracobrachial muscles (Figure 1). Just over the axillary artery towards the direction of the brachial plexus using a peripheral nerve stimulator (Stimuplex HNS11; B.Braun Medical, Germany), and $50 \mathrm{~mm} 22 \mathrm{G}$ insulated needle (Stimuplex, DB Braun Medikal) stimulation current at $1 \mathrm{~mA}$ with a frequency of $2 \mathrm{~Hz}$ is delivered for $0.1 \mathrm{~ms}$ to find the point where combined distal motor response of median, and ulnar nerves is elicited. On the point

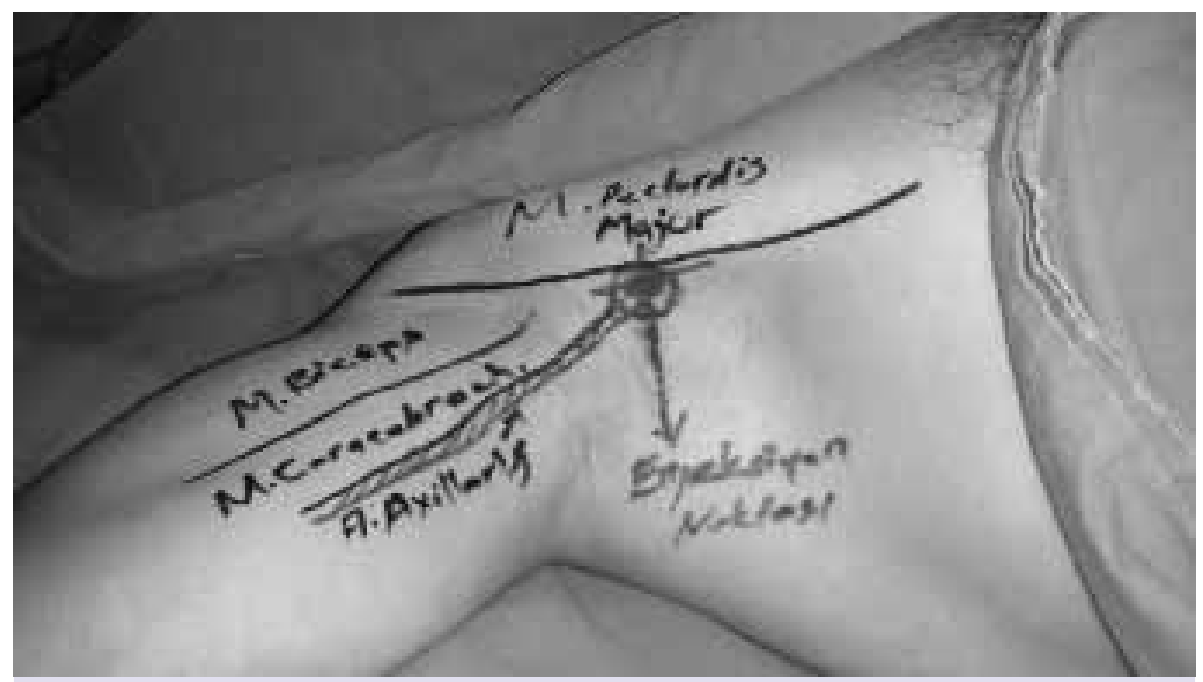

FIGURE 1. Injection site in axillary block. 
where stimulation induced flexion of the index, and middle fingers (median nerve), and the fourth, and fifth digits together with adduction of the thumb (ulnar nerve), current intensity is reduced to 0.5 $\mathrm{mA}$. This degree of motor response is considered to be adequate, and a local anesthetic mixture of $35 \mathrm{ml}$ ( $1 \%$ lidocaine $20 \mathrm{ml}+0.25 \%$ bupivacaine $15 \mathrm{ml}$ ) is injected with aspirations at every $5 \mathrm{ml}$. At the start of the injection, abolishment of motor response following injection of $1 \mathrm{ml}$ local anesthetic solution, and painless intraneural injection are considered as an evidence proving proper placement of the needle, and the rest of the local anesthetic solution is injected at a slower rate. After completion of the injection, the arm is brought to adduction, and arnmpit is compressed for 5 minutes.

The time elapsed from the insertion of the needle into the skin up to the completion of the injection is recorded as block performance time. Sensory block is evaluated at 5., 10, 15, 20, 25., and 30. minutes after completion of the procedure using a short-end needle at all areas innervated by all nerve groups, and recorded as onset time of the sensory block. At the same time points with the sensory block, motor block is evaluated ( $0=$ no block; $1=$ incomplete motor block; $2=$ complete motor block) The time to the first level is recorded as motor block onset time.

If the level of block is not adequate at areas innervated by the nerve groups in the patients brought into the operating room 30 minutes later or tourniquet pain occurs, IV fentanyl $1.5 \mu \mathrm{g} / \mathrm{kg}$ is administered, and if inadequate, additional sedation with $0.5-1 \mathrm{mg} / \mathrm{kg}$ IV propofol is performed. If pain persists despite these measures, then using a laryngeal mask general anesthesia is instituted. These events are recorded in anesthesia monitorization file of the patient. Self-satisfaction level of the patient from the anesthesia (good, moderate, bad, very bad) is inquired in the recovery room, after termination of the operation. Twenty-four hours later, before their discharge, the patients are questioned as for neurological complications.

In our study, data obtained were evaluated regarding block performance time, sensory, and motor block onset time, success rate, complications,
TABLE 1. Demographic date, and types of the operations performed

n

Mean \pm SD

Age (year)

$42.02 \pm 13.04$

Height (cm)

$169.6 \pm 7.85$

Body weight $(\mathrm{kg})$

$78.2 \pm 19.6$

Female/Male

$17 / 23$

Types of operations

Osteosynthesis $\quad 30$

Ganglion cyst 3

Carpal tunnel syndrome 5

Foreign body 1

Lipoma extraction $\quad 1$

Data are shown as mean \pm standard deviation (SD) or number of patients (n).

TABLE 2. Block performance, and onset times (Mean \pm SD)

Mean \pm SD

Block performance time ( $\mathrm{min})$

$1.21 \pm 0.39$

Motor block onset time ( $\mathrm{min})$

$14.20 \pm 4.96$

Sensory block onset time ( $\mathrm{min}$ )

$17.19 \pm 2.71$

requirement for an additional analgesic, and patient's satisfaction. For statistical analysis, SPSS for Windows package program was used. Results were expressed as means plus standard deviation.

\section{RESULTS}

Demographic data, and types of operations are shown in Table 1 . In our case axillary block performance time was $1.21 \pm 0.39 \mathrm{~min}$. Onset times of motor $(14.20 \pm 4.96 \mathrm{~min})$, and sensory block $(17.19 \pm 2.71 \mathrm{~min})$ were also determined (Table 2).

In $7(17.5 \%)$ patients with inadequate analgesia, fentanyl had been used, and in cases with persistent pain $(n=6 ; 15 \%)$, propofol was used to achieve additional analgesia. One patient $(2.5 \%)$ whose ad- 
ditional analgesia, and sedation were inadequate, was switched to general anesthesia. Patient satisfaction was rated as good $(\mathrm{n}=38 ; 95 \%)$, and moderate $(n=2 ; 5 \%)$ None of our patients' satisfaction levels was rated as bad, and very bad (Table 3). In $97.5 \%$ of the patients blocks were achieved successfully with additional analgesics, and sedation without switching to general anesthesia.

Tourniquets were applied intraoperatively in 32 out of 40 patients without inducing pain. Motor block levels were recorded as incomplete $(n=39)$, and complete $(\mathrm{n}=1)$. In 3 patients during application of block, vascular punction was required which did not interrupted the procedure. Any other complication did not developed. Since the patients were hospitalized during resolution of the block, block recovery time could not be evaluated.

Within the first 24 hours following application of block, any complication including hypotension, arrhytmias, nausea, paresthesia, and did not occur, and sensory, and motor functions of all patients recovered without any problem.

\section{DISCUSSION}

Axillary approach to the brachial plexus is a frequently used technique thanks to its easy applicability, close vicinity of the nerves to vascular structures, and lower complication rates $[2,3,6]$. Success in axillary block, depends on injection of the local anesthetic solution to the point nearest to the targeted nerve, concentration, and volume of the anesthetic solution used. Ease, and rapidity of application, and lower complication rates are targeted [7].

Our median block performance time was 1.21 minutes In publications on multiple injection techniques, block performance times for double, and triple-injection techniques have been reported as $5-6$, and $8-13$ minutes, respectively $[6,9,10,11,12$, $13,14]$. Single-injection technique can be evaluated as more advantageous relative to multiple injection techniques in that it has a shorter performance times, and its application is more comfortable both for the patient, and the physician.

In an arm at $90^{\circ}$ abduction, median, and ulnar
TABLE 3. Number of patients who received additional analgesics, and sedation, and those switched to general anesthesia

\begin{tabular}{lcc} 
& $\mathrm{n}$ & $\%$ \\
\hline Additional analgesic Fentanyl & 7 & 17.5 \\
Sedation & 6 & 15 \\
General anesthesia & 1 & 2.5 \\
Patient satisfaction & & \\
$\quad$ Good & 38 & 95 \\
$\quad$ Moderate & 2 & 5 \\
$\quad$ Dissatisfied & 0 & 0 \\
Extremely disssatisfied & 0 & 0
\end{tabular}

superficial, radial, and musculocutaneous nerves moves into deeper structures [2, 15]. Most frequently, when compared with the axillary artery, median nerve is situated more laterally, and ulnar nerve is found at an anteromedial location. While radial nerve is adjacent to posterior aspect of the axillary artery. However various studies have demonstrated potential variations in their anatomical locations $[1,15,16]$. Retzl et al. performed ultrasound-guided studies with volunteers, and demonstrated that location of the nerves in the axillary region can be variable, and these nerves can leave the axillary sheath at the distal end of the pectoralis minor muscle [16]. Thus, they emphasized the need to perform the nerve block, as far as possible, from the most proximal part of the axillary region.

Combined use of short-, and long-acting anesthetic agents reportedly shortens block onset time [4]. In our applications, we also used short-, and long-acting anesthetic agents in combination, and injected anesthetic agent-as far as possible-into the most proximal part of the axillary region. With this approach, sensory block onset time was $17.18 \mathrm{~min}$ utes. In multiple injection techniques, sensory block onset times have been reported to vary between 15 , and 18 minutes. [12, 14, 17]. This time interval appears to comply with our sensory block onset time we achieved with single-injection method In the axillary block technique, success rates changing between 60 , and $100 \%$ have been reported $[3,4,6,10,14$, 
18]. Many reports have indicated that neurovascular region septas within the axillary sheath prevented spread of the local analgesic agents which can cause induction of incomplete blocks $[15,19,20]$. However irrefutable data are lacking about the impact of septas on the spread of local anesthetic agents and whether they prevent distribution of local anesthetic agents or not $[15,21]$. In fact, Partridge et al. injected methylene blue into the axillary sheath of cases with axillary septas, and demonstrated staining of all of medial, ulnar, and radial nerves. [21]. They indicated that owing to the communications between compartments amidst septas, multiple injections are unnecessary in order to achieve axillary block. In their randomized studies, Liu et al. compared single, and double-injection methods using ultrasonographic guidance or nerve stimulator, and could not demonstrate any difference between groups as for block success rates [13]. They revealed that as determinative factors in the success rates of various nerve blocks, the injection point within the sheath of the brachial plexus, an the level of injection might be more important than the technique of multiple injections. They advocated that different rates of block quality, and success reported in their studies could be related to the site, and level of the injections.

In studies where local anesthetic agents more than $30 \mathrm{ml}$ were used, better drug distribution in the axillary region with higher success rates have been demonstrated [22, 23]. Besides, as reported in the literature, local anesthetic agent applied lateral to the median nerve spreads along the axillary artery and easily blocks the musculocutaneous nerve [11, $13,24]$. Still in proportion with the time elapsed after the injection, due to the spread of local anesthetic agent within the axillary sheath, the quality of radial nerve block conceivably increases $[11,13]$.

Our single-injection block technique we applied in our procedures was very successful (97.5\%). Our higher success rate can be attributed to our selection of injection site as the most proximal part of the axillary region, the level of the block, and the volume of injection solution used. We think that with this approach, nerves in the brachial plexus or those leaving the sheath of the plexus at the level of coracoid processus were blocked which increased our success rates.

In conclusion, single -injection axillary block technique which is applied on the region where distal motor responses of median, and ulnar nerves to the neurostimulation (the region innervated both of these two terminal branches of the brachial plexus) is elicited at the same time can be evaluated as a safe method in that it has a shorter block performance time with easily applied technique, lower complication, and higher success rate, and favourable patient satisfaction levels. Therefore we have concluded that axillary nerve block should be brought into agenda, and its use should be encouraged in suitable cases.

Conflict of Interest: No conflict of interest was declared by the authors.

Financial Disclosure: The authors declared that this study has received no financial support.

\section{REFERENCES}

1. Orebaugh SL, Williams BA. Brachial plexus anatomy: normal and variant. ScientificWorldJournal 2009;9:300-12. CrossRef

2. Satapathy AR, Coventry DM. Axillary brachial plexus block. Anesthesiol Res Pract 2011;2011:173796.

3. Coventry DM, Barker KF, Thomson M. Comparison of two neurostimulation techniques for axillary brachial plexus blockade. Br J Anaesth 2001;86:80-3. CrossRef

4. Neal JM, Gerancher JC, Hebl JR, Ilfeld BM, McCartney CJ, Franco CD, et al. Upper extremity regional anesthesia: essentials of our current understanding, 2008. Reg Anesth Pain Med 2009;34:134-70. CrossRef

5. Conceição DB, Helayel PE, Oliveira Filho GR. A comparative study between ultrasound and neurostimulation guided axillary brachial plexus block. [Article in Portuguese] Rev Bras Anestesiol 2009;59:585-91. [Abstract] CrossRef

6. Zencirci B. Comparision of nerve stimulator and ultrasonography as the techniques applied for brachial plexus anesthesia. Int Arch Med 2011;4:4. CrossRef

7. Karaağaçlı MB, Yılmazlar A. Effects of different currents and local anaesthetic volumes in axillary block. Turk Anest Rean Der Dergisi 2005;33:151-7.

8. Sertöz N, Deniz MN, Bayraktaroğlu E, Ayanoğlu HÖ. Çoklu sinir uyarı yöntemi ile uygulanan aksiller brakial pleksus bloğonun geriye dönük değerlendirilmesi. Turk Anest Rean Der Dergisi 2010;38:254-61.

9. Koscielniak-Nielsen ZJ, Stens-Pedersen HL, Lippert FK. Readiness for surgery after axillary block: single or multiple injection techniques. Eur J Anaesthesiol 1997;14:164-71. CrossRef

10. Handoll HH, Koscielniak-Nielsen ZJ. Single, double or mul- 
tiple injection techniques for axillary brachial plexus block for hand, wrist or forearm surgery. Cochrane Database Syst Rev 2006;25:CD003842.

11. Sia S, Lepri A, Ponzecchi P. Axillary brachial plexus block using peripheral nerve stimulator: a comparison between double- and triple-injection techniques. Reg Anesth Pain Med 2001;26:499503. CrossRef

12. Sia S, Bartoli M. Selective ulnar nerve localization is not essential for axillary brachial plexus block using a multiple nerve stimulation technique. Reg Anesth Pain Med 2001;26:12-6. CrossRef

13. Liu FC, Liou JT, Tsai YF, Li AH, Day YY, Hui YL, et al. Efficacy of ultrasound-guided axillary brachial plexus block: a comparative study with nerve stimulator-guided method. Chang Gung Med J 2005;28:396-402.

14. Sia S, Bartoli M, Lepri A, Marchini O, Ponsecchi P. Multipleinjection axillary brachial plexus block: A comparison of two methods of nerve localization-nerve stimulation versus paresthesia. Anesth Analg 2000;91:647-51. CrossRef

15. Klaastad $\varnothing$, Smedby O, Thompson GE, Tillung T, Hol PK, Røtnes JS, et al. Distribution of local anesthetic in axillary brachial plexus block: a clinical and magnetic resonance imaging study. Anesthesiology 2002;96:1315-24. CrossRef

16. Retzl G, Kapral S, Greher M, Mauritz W. Ultrasonographic findings of the axillary part of the brachial plexus. Anesth Analg 2001;92:1271-5. CrossRef
17. Casati A, Danelli G, Baciarello M, Corradi M, Leone S, Di Cianni $\mathrm{S}$, et al. A prospective, randomized comparison between ultrasound and nerve stimulation guidance for multiple injection axillary brachial plexus block. Anesthesiology 2007;106:992-6.

18. Schroeder LE, Horlocker TT, Schroeder DR. The efficacy of axillary block for surgical procedures about the elbow. Anesth Analg 1996;83:747-51. CrossRef

19. Thompson GE, Rorie DK. Functional anatomy of the brachial plexus sheaths. Anesthesiology 1983;59:117-22. CrossRef

20. Ay S, Akinci M, Sayin M, Bektas U, Tekdemir I, Elhan A. The axillary sheath and single-injection axillary block. Clin Anat 2007;20:57-63. CrossRef

21. Partridge BL, Katz J, Benirschke K. Functional anatomy of the brachial plexus sheath: implications for anesthesia. Anesthesiology 1987;66:743-7. CrossRef

22. Rucci FS, Barbagli R, Pippa P, Boccaccini A. The optimal dose of local anaesthetic in the orthogonal two-needle technique. Extent of sensory block after the injection of 20,30 and $40 \mathrm{~mL}$ of anaesthetic solution. Eur J Anaesthesiol 1997;14:281-6. CrossRef

23. Vester-Andersen T, Christiansen C, Sørensen M, Kaalund-Jørgensen HO, Saugbjerg P, Schultz-Møller K. Perivascular axillary block II: influence of injected volume of local anaesthetic on neural blockade. Acta Anaesthesiol Scand 1983;27:95-8. CrossRef

24. Yamamoto K, Tsubokawa T, Shibata K, Kobayashi T. Area of paresthesia as determinant of sensory block in axillary brachial plexus block. Reg Anesth 1995;20:493-7. 